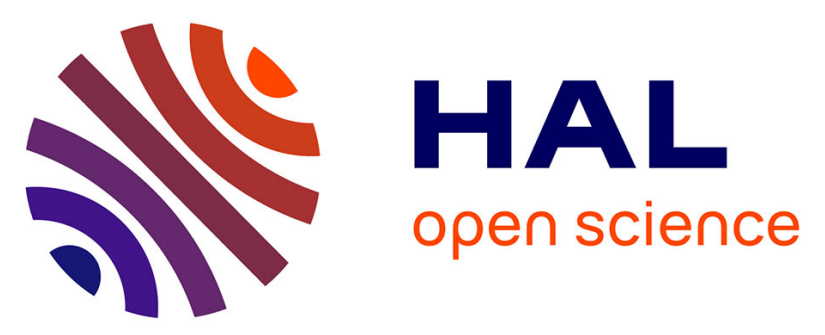

\title{
Plasma disposition of capecitabine and its metabolites 5'DFCR and 5'DFUR in a standard and dose-intensified monotherapy regimen
}

Martin Czejka, J. Schueller, A. Farkouh, B. Gruenberger, W. Scheithauer

\section{To cite this version:}

Martin Czejka, J. Schueller, A. Farkouh, B. Gruenberger, W. Scheithauer. Plasma disposition of capecitabine and its metabolites 5'DFCR and 5'DFUR in a standard and dose-intensified monotherapy regimen. Cancer Chemotherapy and Pharmacology, 2010, 67 (3), pp.613-619. 10.1007/s00280-0101363-4 . hal-00594929

\author{
HAL Id: hal-00594929 \\ https://hal.science/hal-00594929
}

Submitted on 22 May 2011

HAL is a multi-disciplinary open access archive for the deposit and dissemination of scientific research documents, whether they are published or not. The documents may come from teaching and research institutions in France or abroad, or from public or private research centers.
L'archive ouverte pluridisciplinaire HAL, est destinée au dépôt et à la diffusion de documents scientifiques de niveau recherche, publiés ou non, émanant des établissements d'enseignement et de recherche français ou étrangers, des laboratoires publics ou privés. 


\section{Plasma disposition of capecitabine and its metabolites 5'DFCR and 5'DFUR in a standard and dose-intensified monotherapy regimen}

M Czejka $^{1}$, J Schueller ${ }^{2}$, A Farkouh ${ }^{1}$, B Gruenberger ${ }^{2}$ and W Scheithauer ${ }^{3}$

${ }^{1}$ Department of Clinical Pharmacy and Diagnostics, University of Vienna, Althanstrasse 14, A-1090 Vienna, Austria

${ }^{2}$ Department of Internal Medicine and Oncology, Hospital Rudolfstiftung, Boerhaavegasse 13, A-1030 Vienna, Austria

${ }^{3}$ Department of Internal Medicine I \& Cancer Center, Medical University Vienna, Waehringer Guertel 18 - 22, A-1090 Vienna, Austria

Key Words: capecitabine, metabolites, pharmacokinetics, intensified schedule

\section{Correspondence:}

Martin Czejka

Department for Clinical Pharmacy and Diagnostics

University of Vienna

A-1090 Vienna, Althanstrasse 14, Austria

Phone: +431427755577

Fax: +43142779555

E-mail: martin.czejka@univie.ac.at 
Purpose: In view of a potential gain in anticancer activity in advanced colorectal cancer (ACRC), there has been considerable interest in using a higher than the approved standard dose of capecitabine (CCB) combined with oxaliplatin. This pharmacokinetic study was designed to evaluate whether CCB is metabolized at the same extent when administered as a monotherapy in two different dose regimens, comparing standard dose (CCB 1) and intensified dose (CCB 2).

Patients and methods: Seven patients suffering from ACRC received subsequently two CCB schedules: In the standard schedule $1250 \mathrm{mg} / \mathrm{m}^{2} \mathrm{CCB}$ p.o. twice daily for two weeks was administered, after a pause of one week a dose intensified CCB 2 schedule was given: 1750 $\mathrm{mg} / \mathrm{m}^{2} \mathrm{CCB}$ p.o. twice daily for one week to be followed by one week rest. Due to this paired cross over design a direct comparison for each single patient was feasible.

Results: In both schedules, mean peak plasma concentrations of CCB occurred at about 50 min, those of metabolites shortly later (range, 54 - 80 min). Peak plasma concentrations were about $10 \%$ (CCB, DFCR) and $40 \%$ (DFUR) higher in the CCB 2 regimen. According to the higher dose of CCB in the dose intensified regimen (+ $40 \%)$, the $\mathrm{AUC}_{\text {last }}$ values increased by $34 \%$ (CCB), $20 \%$ (DFCR) and $58 \%$ (DFUR), respectively.

Conclusion: The results indicate that higher doses of CCB are metabolized approximately dose-dependent compared to the standard dose. No indices for a saturation of metabolizing processes or any significant delay of elimination rate was observed. The immediate 5FU precursor DFUR was formed at a $50 \%$ higher extent (expressed as $\mathrm{AUC}_{\text {last }}$ values) than in the standard CCB 1 schedule. From the pharmacokinetic point of view this increased formation rate suggests clinical importance in regard to metabolic activation of CCB. 


\section{Introduction}

The oral fluoropyrimidine carbamate capecitabine (CCB) is an equally effective and tolerable, but more convenient alternative to i.v. 5-fluorouracil (5-FU) / folinic acid. In fact, this compound has been designed to generate 5-FU preferentially within the tumour and to mimic continuous infusion of 5-FU [1,2], while having an easier handling [3].

CCB is rapidly and extensively absorbed through the gastrointestinal wall as an intact molecule, and rapidly metabolised to 5-FU via a three-step enzymatic cascade [2,4]. Firstly CCB is metabolized into 5'-deoxy-5-fluorocytidine (DFCR) by the human carboxyesterases isoenzyme 2 (hCES2), primarily in the liver. DFCR is converted to 5'-deoxy-5-fluorouridine (DFUR) by cytidine deaminase (CytDA) in tumor cells and in the liver. Finally, DFUR is metabolized into the cytotoxic 5-FU by thymidine phosphorylase (TP), which is significantly more active in the tumour tissue than in the adjacent healthy tissue [2].

CCB is given either as a single agent or in combination with irinotecan (XELIRI) or oxaliplatin (OxPt; XELOX), which (based on different mechanisms of action) has resulted in increased therapeutic efficacy without major toxic overlap $[5,6]$.

The combination of CCB and OxPt in fact has demonstrated promising synergistic activity in ACRC. Various XELOX regimens using different dosages of CCB from 750 to $2500 \mathrm{mg} / \mathrm{m}^{2}$ have been applied. The most frequently used regimens are CCB $1000 \mathrm{mg} / \mathrm{m}^{2}$ p.o. twice daily for 14 days plus OxPt $130 \mathrm{mg} / \mathrm{m}^{2}$ i.v. on day 1 every 3 weeks [7] or CCB $1000 \mathrm{mg} / \mathrm{m}^{2}$ p.o. twice daily for 14 days plus OxPt $70 \mathrm{mg} / \mathrm{m}^{2}$ i.v. once every week [8]. A modified XELOX schedule using dose intensified CCB $\left(3500 \mathrm{mg} / \mathrm{m}^{2}\right.$ for one week; so called XELOX 2 schedule) was first described by Scheithauer et al [9] and is now being investigated in several clinical trials.

For OxPt and bevacizumab, no influence on the pharmacokinetics of CCB standard dose was documented $[10,11]$. However until today only preliminary pharmacokinetic data of CCB after dose intensification have been described [12] and it remains unclear whether saturation processes of enzymes affect sequential biotransformation of CCB into DFUR after higher doses of CCB. In this article we describe the pharmacokinetics and metabolism of CCB when given as a monotherapy at a standard dose of $2500 \mathrm{mg} / \mathrm{m}^{2}$ p.o. daily for two weeks (CCB 1) compared to an intensified dose of $3500 \mathrm{mg} / \mathrm{m}^{2}$ daily for 7 days (CCB 2). 


\section{Clinical study}

\section{Subjects}

Seven patients ( 2 female, 5 male) who received palliative chemotherapy for ACRC entered this pharmacokinetic study. Their mean age was 67.8 years (range 57 - 77), mean body mass was $78.4 \pm 17.2 \mathrm{~kg}$ (range $48-104$ ) and mean body surface area was $1.9 \pm 0.2 \mathrm{~m}^{2}$ (range $(1.41-2.25)$.

Each patient provided written informed consent according the specifications of the local ethics committee. Inclusion criteria were as follows: ECOG performance status 0 - 1; white blood cell count $\geq 4000 / \mu 1$, ANC $\geq 1500$; no renal impairment as judged by standard biochemical parameters (serum creatinine $\leq 1.3 \mathrm{mg} / \mathrm{dl}$ ); and adequate hepatic function i.e. bilirubin $\leq 1.2 \mathrm{mg} / \mathrm{dl}$, and SGOT, SGPT $\leq 2.5$ fold U/l ( 5 fold acceptable in case of liver mets, but not reached in this study). In terms of liver function it has already been clarified that mild to moderate impairment caused by liver metastases do not significantly change the PK of CCB and its metabolites [13].

\section{Drugs}

Capecitabine (Xeloda ${ }^{\circledR}$ ) was supplied from Hoffmann La Roche (Vienna, Austria) as filmcoated tablets in two dose strengths: $150 \mathrm{mg}$ and $500 \mathrm{mg}$, which were not to be split and had to be taken with water within $30 \mathrm{~min}$ after the ingestion of food. Compliance with the oral medication regimen was assessed in the hospital.

Pure chemical standard substances (CCB, DFCR, DFUR) were donated by Hoffmann La Roche (Basle, Switzerland) for calibration purposes of the analytical assay.

\section{Chemotherapy schedule}

Table 1 displays the two different chemotherapeutic drug dose schedules, which were investigated consecutively in all patients. By this paired cross over design with intra-patient comparison each subject served for its own control.

table 1

\section{Blood samples}

Blood samples of $5 \mathrm{ml}$ were drawn from the cubital vein at the following times: 0, 30, 60, 90, 120, 180 and 210 min after ingestion of the oral CCB morning dose. Samples were collected in sodium-heparinized vacutubes and blood cells were separated by centrifuging at $2500 \mathrm{rpm}$ for 5 minutes. Of the supernatant $2.0 \mathrm{ml}$ were frozen at $-80{ }^{\circ} \mathrm{C}$ until analysis. 
Sampling was performed in the first week following CCB 1 standard dose on day one and five. After crossing over to CCB 2 (dose intensified schedule) sampling was repeated during the $4^{\text {th }}$ week, again on day one and five. Since no cumulative effect from day one to five was observed, the respective data from the seven patients were summarised/analysed together $(\mathrm{N}=14)$.

\section{Sample clean-up and analytics}

Separation of analytes from matrix compounds was performed by a sensitive and selective solid phase extraction method using Oasis® HLB C18 cartridges (Waters Inc.). For quantification of CCB, DFCR and DFUR in plasma samples we used reversed phase high performance liquid chromatography as previously reported [14,15]. External calibration was performed by using pooled human plasma samples spiked with pure chemical standards.

\section{Biometric calculations}

Curve fitting of plasma concentration versus time date was performed by the pharmacokinetic software WinNonlin Professional 4.0 (Pharsight Corporation, CA 94041, USA) using the Nelder-Mead nonlinear iterative least square algorithm. For pharmacokinetic modeling of CCB and metabolites, a non-compartment model with extravascular input (model 3 of the WinNonlin library) was chosen. For calculation of AUC and AUMC the linear trapezoidal rule was applied for the ascending part of the concentration-time curve and the log-linear trapezoidal rule for the descending part of the concentration-time curve.

The following pharmacokinetic parameters had been calculated for CCB, DFCR and DFUR, ( $\mathrm{Vz}$ and $\mathrm{Cl}_{\text {tot }}$ were not calculated for CCB metabolites).

$\begin{array}{ll}\mathrm{t}_{\max } & \text { time of peak plasma concentration [min] } \\ \mathrm{c}_{\max } & \text { peak plasma concentration }[\mu \mathrm{g} / \mathrm{ml}] \\ \mathrm{c}_{\text {last }} & \text { last measurable drug concentration }[\mu \mathrm{g} / \mathrm{ml}] \\ \lambda \mathrm{z} & \text { terminal elimination-rate }\left[\mathrm{min}^{-1}\right] \\ \mathrm{t}_{1 / 2} \lambda \mathrm{z} & \text { half-life of terminal elimination }[\mathrm{min}] \\ \mathrm{AUC}_{\text {last }} & \text { area under the concentration-time curve from } 0 \text { to } \mathrm{c}_{\text {last }}[\mu \mathrm{g} / \mathrm{ml} * \mathrm{~min}] \\ \mathrm{AUC}_{\text {inf }} & \text { area under the concentration-time curve from } 0 \text { to infinity }[\mu \mathrm{g} / \mathrm{ml} * \mathrm{~min}] \\ \mathrm{Vz} & \text { volume of distribution }[1] \\ \mathrm{Cl}_{\text {tot }} & \text { total body clearance }[1 / \mathrm{min}] \\ \mathrm{MRT}_{\text {last }} & \text { mean-residence time from } 0 \text { to c cast }[\mathrm{min}]\end{array}$


To obtain the percent $\mathrm{AUC}$ amount of metabolite $\left[\mathrm{AUC}_{\mathrm{met}}\right]$, the $\mathrm{AUC}_{\text {last }}$ values of each metabolite (5'DFCR, 5'DFUR) were compared with the sum of AUCs as follows:

$$
\mathrm{AUC}_{\text {met }}[\%]=\frac{\mathrm{AUC}_{\mathrm{met}} * 100}{\mathrm{AUC}_{\mathrm{CCB}+\mathrm{DFCR}+\mathrm{DFUR}}}
$$

An apparent formation-coefficient of the metabolites catalyzed by hCES [ $\left.\mathrm{R}_{\mathrm{hCES}}\right]$ or CytDA $\left[\mathrm{R}_{\mathrm{CytDA}}\right]$, respectively, has been calculated by dividing the metabolite $\mathrm{AUC}_{\text {last }}$ by its precursors $\mathrm{AUC}_{\text {last }}$ :

$$
\begin{aligned}
& \mathrm{R}_{\mathrm{hCES}}=\frac{\mathrm{AUC}_{\mathrm{DFCR}}}{\mathrm{AUC}_{\mathrm{CCB}}} \\
& \mathrm{R}_{\mathrm{CytDA}}=\frac{\mathrm{AUC}_{\mathrm{DFUR}}}{\mathrm{AUC}_{\mathrm{DFCR}}}
\end{aligned}
$$

Descriptive statistics of plasma concentrations and of pharmacokinetic data of all compounds was calculated by use of the scientific softwares Graph Pad Prism 5.0 and InStat 3.0 for Windows (Graph Pad Software, San Diego, CA 92130, USA). Probable statistical outliers in data sets had been verified by the Grubb`s test using the extreme studentized deviate method. Potential statistically significant differences in plasma concentrations or pharmacokinetic parameters between both CCB schedules, were evaluated by use of the independent Student's t-test (two sided, paired, homoscedastic, p-level 0.05).

\section{Results}

Mean plasma concentrations time curves of all compounds are depicted in figure 1: Compared to $\mathrm{CCB} 1$, mean plasma concentrations of $\mathrm{CCB}$ and metabolites were distinctly higher in the CCB 2 dose intensified regimen. Plasma profiles showed a great interpatient variability because CCB plasma concentrations time curves were abnormally high in two patients ( 2 and 3). Mean CCB peak concentration occurred between 30 and 60 min after ingestion of tablets in the CCB 1 schedule, indicating a rapid release from the tablet and fast resorption of CCB into the blood stream. After CCB 2, peak plasma concentrations CCB occurred shortly later at about $60 \mathrm{~min}$.

Compared to standard dose (CCB 1), $\mathrm{t}_{\max }$ was almost identical in the CCB 2 schedule: $+4 \%$ $\mathrm{CCB},+19 \% \mathrm{DFCR}$ and $+6 \%$ DFUR. 


\section{figure 1}

Peak concentrations of CCB and DFCR occurred within 60 min after ingestion of tablets showing that DFCR was formed rapidly from CCB without any delay. DFUR concentrations in plasma were about two times higher than those of CCB while DFCR concentrations were very similar to those of CCB. In both regimens peak concentrations of DFUR occurred about half an hour later; this can be explained by the cascade metabolism of CCB with DFCR as the intermediate metabolite which itself represents the precursor for DFUR formation. After having reached its maximum, plasma concentrations of all compounds declined slowly. Insert $\mathrm{C}$ in the lower part of figure 1 shows the sum of plasma concentrations of $\mathrm{CCB}$ and metabolites: as can be seen from this concentration time curve for the CCB 2 schedule, the sum of plasma concentrations was nearly $50 \%$ higher than in the standard CCB 1 schedule. Mean factor obtained after dividing plasma concentrations high/low was 1.32 (range from 1.16 to 1.67 ) and this factor correlated closely with the dose factor of 1.40 (CCB 2 versus CCB 1).

Mean logarithmic plasma concentration decay of the sum of CCB plus metabolites was strongly linear: see insert D in lower part of figure 1. For both schedules slope (k) and coefficient of regression line $(R)$ were very similar: $k=-0.095$ for CCB $1(R=0.961, p=$ $0.0023)$ and $\mathrm{k}=-0.134$ for CCB $2(\mathrm{R}=0.969, \mathrm{p}=0.0015)$.

Table 2 presents an overview for the non-compartment pharmacokinetic data of CCB, DFCR and DFUR obtained in both schedules.

table 2

Peak plasma concentrations of DFUR were significantly higher $(+51 \%, p<0.05)$ in the dose intensified CCB 2 schedule, while CCB and DFCR maximum concentrations only differed by $15 \%$ (CCB) and $10 \%$ (DFCR), respectively. In both schedules, $c_{\text {last }}$ values of all three compounds were very similar, indicating that distribution, metabolic and elimination processes have completed already after 3 hours. The intensified CCB 2 dose obviously does not cause an inhibition of these ADME processes.

The PK parameters $t_{1 / 2} \lambda z$ and MRT of CCB were in the same order of magnitude in both regimens. Contrary to CCB, half-lives of DFCR and DFUR showed a great inter-patient variability represented by high standard deviations of $\lambda z, t_{1 / 2} \lambda z$ and MRT. 
$\mathrm{AUC}_{\text {last }}$ and $\mathrm{AUC}_{\mathrm{inf}}$ values differed distinctly between the two CCB schedules: $+34 \%$ for $\mathrm{CCB},+20 \%$ for DFCR and $+58 \%$ for DFUR; the latter difference was statistically significant $(\mathrm{p}<0.05)$. These changes in $\mathrm{AUC}_{\text {last }}$ values correlated very close to the percent changes in $\mathrm{c}_{\max }$ values with a coefficient of correlation $\mathrm{R}=0.966$. Percent distribution of AUCs $_{\text {last }}$ in CCB 1 (2) was 28 (26) : 29 (25) : 43 (49) percent, a similar proportion in both regimens.

Contrary to pharmacokinetic data, the apparent formation rates of DFCR and DFUR were close together (see figure 2), only a single patient had been identified as a statistic outlier by Grubbs test. Any increase of these R values indicates a higher apparent formation rate of metabolites. So after high dose of CCB, more DFCR and DFUR are generated enzymatically by hCES and CytDA.

figure 2

\section{Discussion}

The aim of this pharmacokinetic study was to determine the plasma disposition and PK parameters of $\mathrm{CCB}$ and its metabolites using the approved standard single dose of 2500 $\mathrm{mg} / \mathrm{m}^{2} / \mathrm{d}$ (CCB 1) compared to a dose intensified schedule of $3500 \mathrm{mg} / \mathrm{m}^{2} / \mathrm{d}$ (CCB 2). Such dose intensification in combination with oxaliplatin was first described in the clinical setting by Scheithauer et al [16] in a randomized phase II trial in ACRC, which was based on preclinical data in human tumor xenografts. In this study the - so called - XELOX 2 regimen was defined as bimonthly oxaliplatin $85 \mathrm{mg} / \mathrm{m}^{2}$ combined with CCB $1750 \mathrm{mg} / \mathrm{m}^{2}$ bid for seven days repeated every two weeks. A superior outcome with higher response rates and longer progression free survival compared to standard XELOX was described. Meanwhile, this modified XELOX schedule with CCB dose intensification has been / continues to be investigated in several clinical trials: Gruenberger et al [17] used the XELOX 2 schedule combined with bevacizumab in a phase II trial of ACRC patients with potentially resectable liver metastases as neoadjuvant treatment. In the first US trial using a higher CCB dose (3000 $\mathrm{mg} / \mathrm{m}^{2}$ for one week) combined with oxaliplatin and bevacizumab, this (A - ICOX) regimen was found to be fairly good tolerated, and a phase III trial comparing this schedule and standard XELOX was initiated [18]. Recently Kornek et al [19] presented preliminary data of a randomized phase II trial combining XELOX 2 and bevacizumab every two weeks in ACRC until progression (PD) versus its use for a limited treatment duration followed by reinduction upon PD. These examples of clinical trials underline the need for testing the PK 
of CCB and its metabolites at a dose which is about $40 \%$ higher than the approved single dose of CCB.

In our study $\mathrm{c}_{\max }$ of $\mathrm{CCB}$ occurred earlier than described in the investigators brochure (this brochure reports $t_{\max }$ values in the range of 2 hours): 0.49 hours for CCB 1 and merely identical 0.51 hours for CCB 2. The higher dose obviously does not delay the absorption rate of CCB into the blood stream. However, the differences in $t_{\max }$ compared to the investigators data remain unclear, probably there are galenic factors leading to a modified release of the drug.

As with other cytotoxic drugs, the inter-patient variability of the pharmacokinetic parameters of CCB and metabolites in this study was high. Coefficients of variance ranged from $36 \%$ to $142 \%$ for plasma concentrations and are likely to be related to the variable expression of enzymes responsible for CCB biotransformation.

CytDA has high activity in hepatocytes, therefore large amounts of DFUR can be measured in plasma after the first liver passage of CCB. Due to this high enzymatic activity, the higher dose of CCB in the dose intensified CCB 2 schedule leads to the corresponding large amounts of the metabolite in the blood. CES in contrary has much lower enzymatic activity, therefore a smaller increase of the plasma concentration of DFCR has been observed in the CCB 2 regimen in our study.

In our study the apparent formation rate of DFUR did not show a high variation of CytDA activity. But recently an over-expression of $180 \%$ of CytDA activity compared to general population values has been reported [20]. Such a high enzymatic activity may lead to unexpected and severe toxicities. Therefore it could be of clinical importance not only to evaluate phenotyping of TP but also of CytDA in order to improve safety of Xeloda regimens.

The pharmacokinetics of CCB and its metabolites have been evaluated extensively in patients [21, 22, 23, 24], but from 500 to $2500 \mathrm{mg} / \mathrm{m}^{2} / \mathrm{d}$ only. Over this range, the pharmacokinetics of CCB and its metabolite, 5'-DFCR were dose proportional and did not change over time. The increases in the AUCs of 5'-DFUR and 5-FU, however, were greater than proportional to the increase in dose and the AUC of 5-FU was 34\% higher on day 14 than on day 1. CCB reached peak blood levels in about 1.5 hours (tmax) with peak DFUR levels occurring slightly later, at 2 hours. In this study, no difference between standard CCB 1 and the dose intensified CCB 2 schedule concerning the fate of CCB and its metabolites in the body was found. 
Assuming the AUC's of CCB + DFCR + DFUR as 100\%, the percentage of the respective AUC “CCB 2" versus "CCB 1" was nearly identical for CCB $26 \%$ versus $27 \%$, for DFCR $26 \%$ versus $29 \%$, for DFUR $48 \%$ versus $44 \%$. The same effect could be demonstrated for each of 7 concentration time points. Therefore, from the pharmacokinetic point of view, dose escalation of CCB seems feasible as no significant change of its metabolic conversion could be documented. Safety and efficacy of XELOX 2 using a dose intensification of CCB is currently investigated in several clinical trials. 


\section{References}

1. Miwa M, Ura M, Nishida M (1998) Design of a novel oral fluoropyrimidine carbamate, capecitabine, which generates 5FU selectively in tumors by enzymes concentrated in human liver and cancer tissue. Eur J Cancer 34:1274-1281

2. Schüller J, Cassidy J, Dumont E, Roos B, Durston S, Banken L (2000) Preferential activation of capecitabine in tumor following oral administration to colorectal cancer patients. Cancer Chemother Pharmacol 45:291-297

3. Mayer RJ (2007) Should capecitabine replace infusional fluorouracil and leucovorin when combined with oxalilpatin in metastatic colorectal cancer. J Clin Oncol 25:4165-4167

4. Kono A, Hara Y, Sugata S, Karube Y, Matsushima Y, Ishitsuka H (1983) Activation of 5'deoxy-5-fluorouridine by thymidine phosphorylase in human tumours. Chem Pharm Bull (Tokyo) 31:175-178

5. Twelves C (2002) Capecitabine as first-line treatment in colorectal cancer. Pooled data from two large, phase III trials. Eur J Cancer 38 (Suppl 2):15-20

6. Cassidy J, Tabernero J, Twelves C, Brunet R, Butts C, Conroy T, Debraud F, Figer A, Grossmann J, Sawada N, Schöffski P, Sobrereo A, Van Cutsem E, Díaz-Rubio E (2004) XELOX (capecitabine plus oxaliplatin): active first-line therapy for patients with metastatic colorectal cancer. J Clin Oncol 22: 2084-2091

7. Cassidy J. Clarke S, Diaz-Rubio E, Scheithauer W, Figer A, Wong R, et al (2008) Randomized phase III study of capecitabine plus oxaliplatin compared with fluorouracil/folinic acid plus oxaliplatin as first-line therapy for metastastic colorectal cancer. J Clin Oncol 26:2006-2012

8. Porschen R, Arkenau HT, Kubicka S, Greil R, Seufferlein T, Freier W, Kretzschmar A, Graeven U, Grothey A, Hinke A, Schmiegel W, Schmoll HJ (2007) Capecitabine plus oxaliplatin compared with fluorouracil and leucovorin plus oxaliplatin: A randomized comparison in metastatic colorectal cancer - A final report of the AIO colorectal study group. J Clin Oncol 20:4217-4223

9. Scheithauer W, Kornek G, Raderer M, Schuell B, Schmid K, Längle F, Huber H (2002) Intermittent weekly high-dose capecitabine in combination with oxaliplatin: a phase I/II study first line treatment of patients with advanced colorectal cancer. Ann Oncol 13: 1583-1589

10. Brennan B, Siu L, Dhesy-Thind B, Cripps C, Gandhi A, Abt M, Smith K, Rittweger K, Hussain S, Choudhury S (2007) Pharmacokinetic interactions between capecitabine, 
oxaliplatin and bevacizumab when used in combination for first line treatment of metastatic colorectal cancer (MCRC). Proc ASCO 25: 18S (abstr. 2554)

11. Schueller J, Czejka M, Farkouh A, Ettlingher D, Aigner K, Grünberger B (2008) Influence of bevacizumab on pharmacokinetics and metabolism of capecitabine in metastatic colorectal cancer. $19^{\text {th }}$ ICACT Congress on Anticancer Treatment (Paris) (abstr. PO 118)

12 Schueller J, M. Czejka, Farkouh A, Ettlinger D, Krexner E, Gruenberger B (2008) Does dose escalation of capecitabine influence its metabolic conversion in metastatic colorectal cancer patients. Proc. ASCO G.I. (abstr. 433).

13. Twelves C, Glynne-Jones R, Cassidy J et al (1999) Effect of hepatic dysfuntion due to liver metastases on the pharmacokinetics of capecitabine and its metabolites. Clin Cancer Res 5:1696-1702

14. Zufía L, Aldaz A, Giráldez J (2004) Simple determination of capecitabine and its metabolites by liquid chromatography with ultraviolet detection in a single injection. $\mathrm{J}$ Chromatogr (B) 809:51-55

15. Farkouh A (2004) Pharmacolinetics and metabolism of capecitabine combined with oxaliplatin: in-vitro and in-vivo investigations. doctoral thesis, University of Vienna

16. Scheithauer W, Kornek G, Raderer M, Schuell B, Schmid K, Kovats E, Schneeweiss B, Lang F, Lenauer A and Depisch D (2003) Randomized multicenter phase II trial of two different schedules of capecitabine plus oxaliplatin as first-line treatment in advanced colorectal cancer. J Clin Oncol 21:1307-1312

17. Gruenberger B, Tamandl D, Schueller J, Scheithauer W, Zielinski CH, Herbst F, Gruenberger T (2008) Bevacizumab, capecitabine, and oxaliplatin as neoadjuvant therapy for patients with potentially curable metastatic colorectal cancer. J Clin Oncol 26: 1830-35

18. Lembersky BC, Sehgal R, Rajasenan KK, Crandall TL, Balaban EP, Pinkerton RA, et al (2008) Phase II study of bevacizumab (BEV), weekly (wkly) intermittent capecitabine (Cap), and oxaliplatin (Ox) on an every-2-week schedule for patients with untreated advanced colorectal cancer (CRC). Proc. Am Soc Clin Oncol 26:1932 (abstr.4061)

19. Kornek G, Schueller J, Schaberl-Moser R, Keil F, Andel J, Renner F, Eisterer W, Balcke P, Scheithauer W (2009) Limited treatment duration and re-induction of the same regimen upon progression versus treatment until progession with Xelox + bevacizumab in patients with advanced colorectal cancer. Ann Oncol 20 (Suppl. 7): abstr. p-0133

20. Mercier C, Duouis C, Blesius A, Fanciullino R, Guang Yang C, Padovani L, Gacometti S, Frances N, Iliadis A, Duffaud F, Ciccolini J (2009) Early severe toxicities after 
capecitabine intake: possible implication of a cytidine deaminase extensive metabolizer profile. Cancer Chemother Pharmacol 63: 1177-1180

21. Reigner B., Blesch K., Weidekamm E (2001) Capecitabine; a review of its clinical pharmacokinetics. Clin Pharmacokinet 40: 85-104

22. Igbal S, Lenz HJ (2004) Capecitabine: the new generation of fluoropyrimidines in colorectal cancer. Expert Rev of Anticancer Ther 4 (6) 947-955

23. Gieschke R, Burger HU, Reigner B, Blesch KS, Steimer JL (2003) Population pharmacokinetics and concentration-effect relationships of capecitabine metabolites in colorectal cancer patients. Br J Clin Pharmacol 55 (3) 252-263

24. Guichard SM, Macpherson JS, Mayer I, Reid E, Muir M, Dodds M, Alexander S, Jodrell DI (2007) Gene expression predicts differential capecitabine metabolism, impacting on both pharmacokinetics and antitumour activity. Eur J Cancer 44(2) 310-317 
Legends of tables and figures

Table 1: Applied capecitabine treatment schedules

Table 2: Mean pharmacokinetic parameters $( \pm \mathrm{SD})$ of CCB, DFCR and DFUR

Figure 1: Mean plasma concentration time curves in the CCB 1 (A) and CCB 2 (B) schedule, the sum of CCB, DFCR and DFUR plasma concentrations in CCB 1 and CCB 2 (C) and log plasma concentrations of the sum of CCB, DFCR and DFUR (D)

Figure 2: AUC ratios (geometric mean $+95 \% \mathrm{CI}$ ) representing apparent formation rates of DFUR and DFCR 


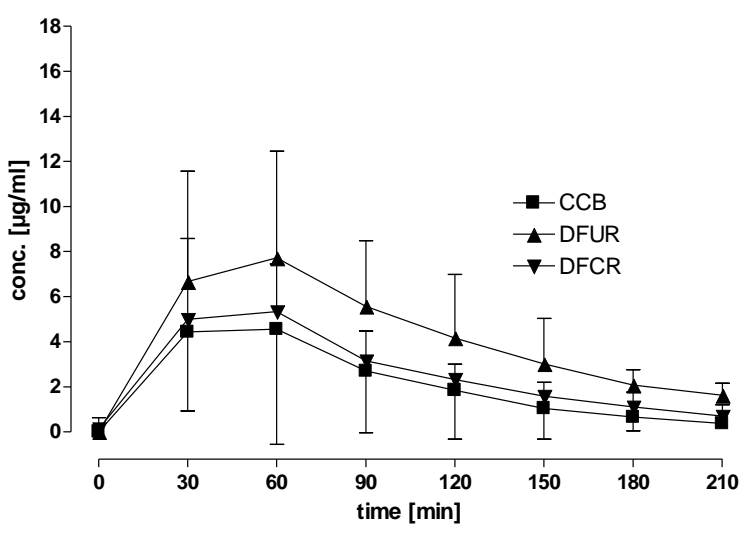

C

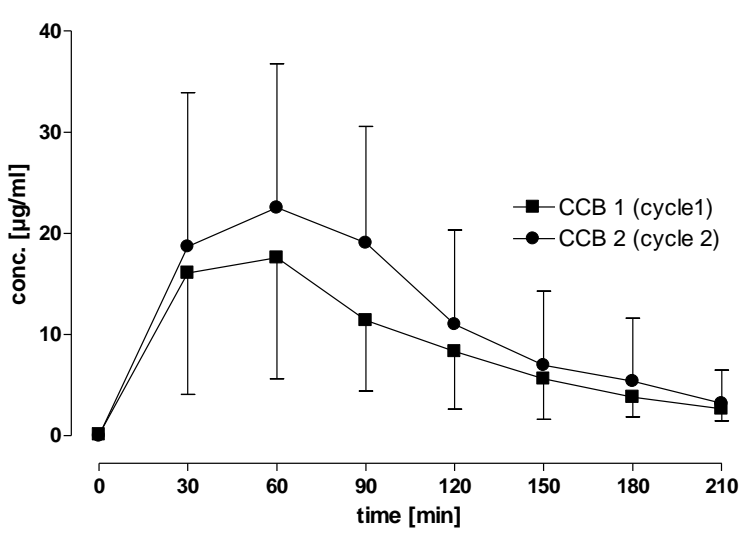

B

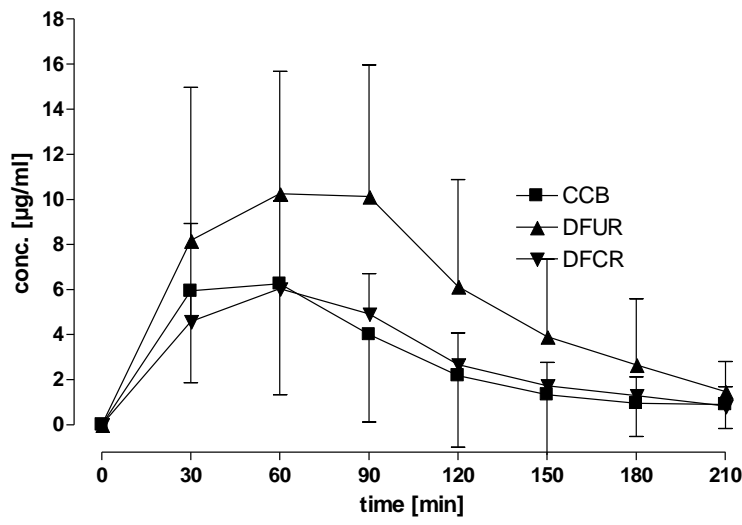

D

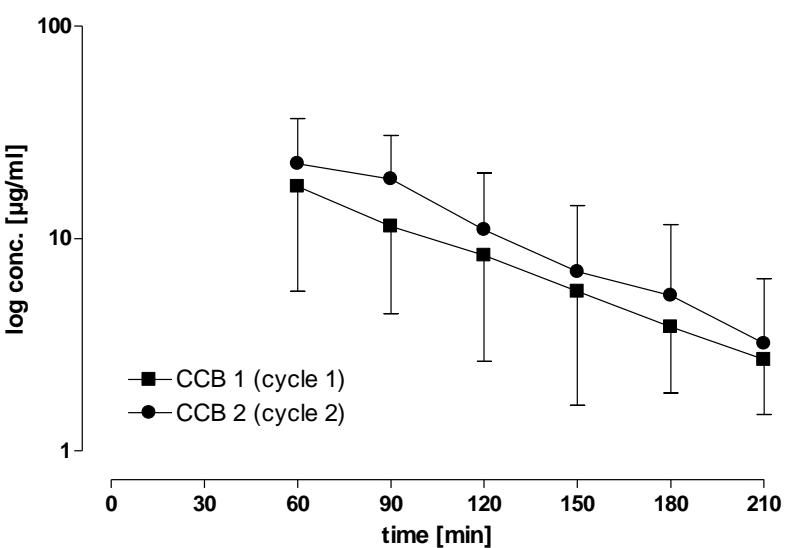




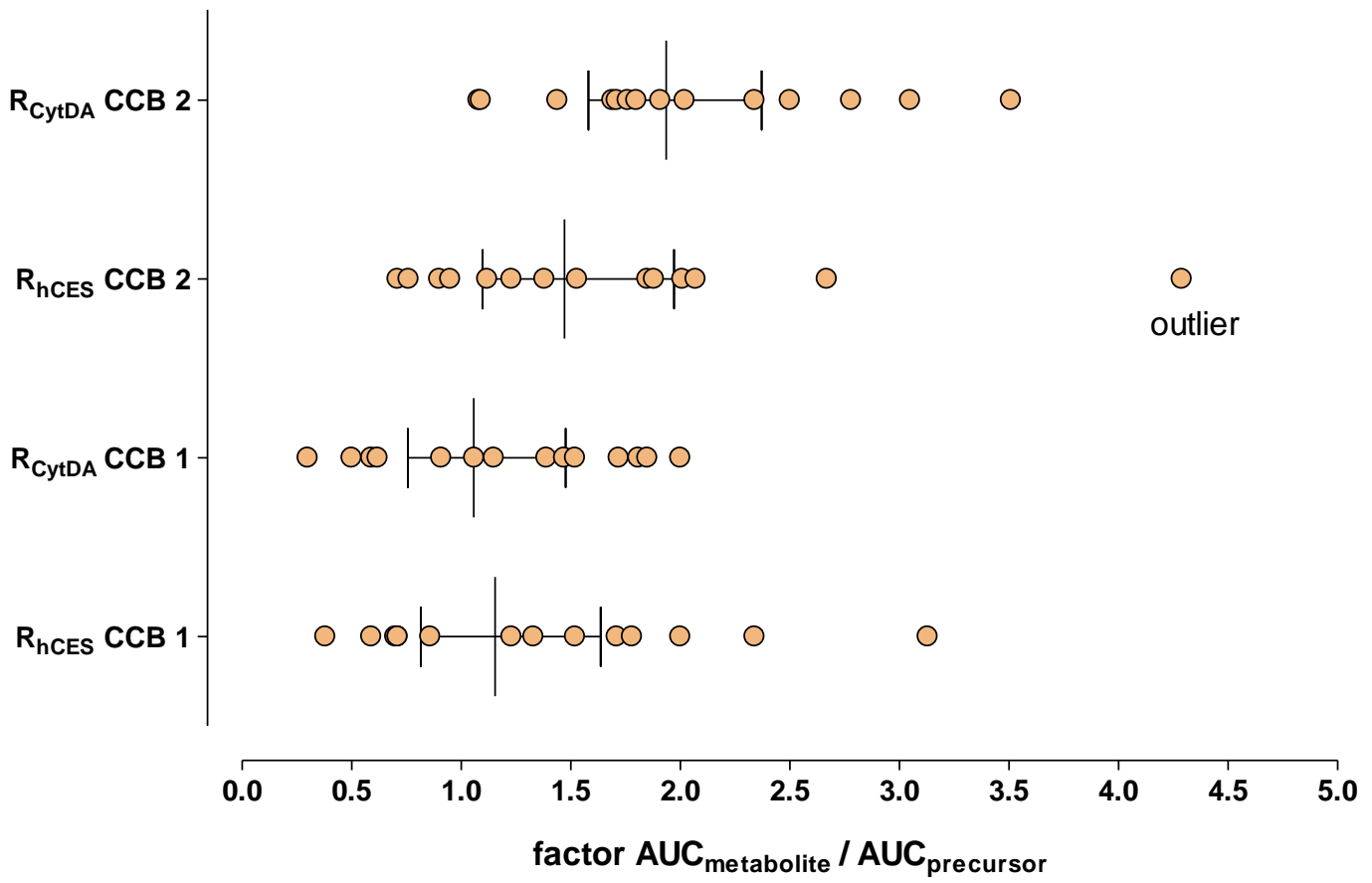

day CCB 1: $\quad$ CCB 2:

$1-141250 \mathrm{mg} / \mathrm{m}^{2}$ p.o. twice daily $12 \mathrm{~h}$

apart, $30 \mathrm{~min}$ after ingestion of

food

$21-27$

$1750 \mathrm{mg} / \mathrm{m}^{2}$ p.o. twice daily $12 \mathrm{~h}$

apart, $30 \mathrm{~min}$ after ingestion of

food

Table 2: Mean pharmacokinetic parameters $( \pm$ SD) of CCB, DFCR and DFUR

\begin{tabular}{|c|c|c|c|c|c|c|}
\hline parameter & $\begin{array}{r}\mathrm{CCB} \\
\mathrm{CCB} 1 \\
\end{array}$ & CCB 2 & $\begin{array}{l}\text { DFCR } \\
\text { CCB } 1 \\
\end{array}$ & CCB 2 & $\begin{array}{l}\text { DFUR } \\
\text { CCB 1 }\end{array}$ & \\
\hline $\mathrm{c}_{\max }$ & $7,57(4,36)$ & $8,68(4,71)$ & $6,50(2,83)$ & $7,05(3,98)$ & $9,34(4,07)^{*}$ & 14 \\
\hline $\mathrm{t}_{\max }$ & $49(22)$ & $51(30)$ & $54(17)^{*}$ & $64(33)$ & $69(37)$ & \\
\hline $\mathrm{c}_{\text {last }}$ & $0,43(0,52)$ & $0,56(0,76)$ & $0,96(0,64)$ & $1,01(0,96)$ & $2,70(1,83)$ & 2, \\
\hline$\lambda \mathrm{z}$ & $0,032(0,014)$ & $0,029(0,011)$ & $0,015(0,006)$ & $0,014(0,007)$ & $0,013(0,018)$ & $0,01 \xi$ \\
\hline $\mathrm{t}_{1 / 2} \lambda \mathrm{z}$ & $26(11)$ & $28(12)$ & $42(24)$ & $61(39)$ & $63(60)$ & \\
\hline $\mathrm{AUC}_{\text {last }}$ & $507(325)$ & $681(511)$ & 532 (191) & $638(273)$ & $793(318)^{*}$ & 12 \\
\hline
\end{tabular}




\begin{tabular}{c|rr|rr|rr}
\hline $\mathrm{AUC}_{\text {inf }}$ & $554(340)$ & $707(544)$ & $593(190)$ & $843(557)$ & $1197(449)$ & 14 \\
$\mathrm{Vz}$ & $217(112)$ & $259(218)$ & $\mathrm{nc}$ & $\mathrm{nc}$ & $\mathrm{nc}$ \\
$\mathrm{Cl}_{\text {tot }}$ & $5,55(2,47)$ & $6,24(3,49)$ & $\mathrm{nc}$ & $\mathrm{nc}$ & $\mathrm{nc}$ \\
$\mathrm{MRT}_{\text {last }}$ & $67(28)$ & $75(26)$ & $95(36)$ & $152(129)$ & $168(146)$ \\
\hline
\end{tabular}

nc ... not calculable

* ... p-level between CCB 1 and CCB $2(\mathrm{p}<0,05)$ 